\title{
ASSESSMENT OF CLOUD COVER CHARACTERISTICS OVER CALIBRATION TEST SITES USING MODIS CLOUD MASK PRODUCTS
}

\author{
H. Yamamoto ${ }^{1}$, S. Tsuchida ${ }^{1}$ \\ ${ }^{1}$ Geological Survey of Japan, AIST - (hirokazu.yamamoto, s.tsuchida)@aist.go.jp
}

Commission III, WG III/10

\begin{abstract}
KEY WORDS: Vicarious calibration, Calibration sites, Railroad valley playa, Clear sky ratio, MODIS cloud mask product,
\end{abstract} MOD35_L2, MYD35L2

\begin{abstract}
:
Spaceborne remotely sensed data can provide the spatial, spectral, and temporal coverage for earth monitoring. Radiometric calibration is indispensable for the accurate higher level products derived from satellite optical sensors, and the long-term radiometric calibration has a crucial role. Especially, vicarious calibration is currently the most accurate method to conduct the radiometric calibration of satellite optical sensors. Various organization and projects have been conducting the vicarious calibration experiments for satellite optical sensors. Railroad valley playa is the most popular calibration site, and we have been also acquiring the vicarious calibration data for Terra ASTER there from the past. Recently, RadCalNet (Radiometric Calibration Network) is open to the public, which is an initiative of the CEOS WGCV. Railroad valley is also one of the RadCalNet sites, and our calibration site is located at the adjacent area. Understanding the cloud cover characteristics over calibration test sites is very important for vicarious calibration and automated facilities measurement. This research evaluates the clear sky ratio for Railroad valley playa using Terra an Aqua MODIS cloud mask product (MOD35_L2 and MYD35_L2) since 2000.
\end{abstract}

\section{INTRODUCTION}

Many researches related with environmental monitoring use data obtained by satellite optical sensors, and radiometeric accuracy is very important for deriving the biophysical parameters. Therefore, radiometric calibration has a key role in the accuracy of higher level products obtained by satellite optical sensors. Vicarious calibration is one of techniques of radiomteric calibration for satellite sensors(Slater et al., 1996).

The reflectance factor on the ground, temperature, atmospheric parameters, and so on are obtained for estimeting the top of atmosphere (TOA) reflectances when target satellite sensor flies over the specific site (Desert, Salt Lake, and so on). It is desirable to have much data obtained over the calibration sites as possible due to the repeat cycle of the satellite. Hence, recently, the Infrared and Visible Optical Sensors subgroup of the Committee on Earth Observation Satellite (CEOS) Working Group on Calibration and Validation (WGCV) set up the radiometric test sites network, the Radiometric Calibration Network (RadCalNet, https://www.radcalnet.org), which provides the TOA reflectances from $380 \mathrm{~nm}$ to $2500 \mathrm{~nm}$ at a $10 \mathrm{~nm}$ spectral sampling interval(Czapla-Myers et al., 2016).

We have conducted vicarious calibration experiments for Terra ASTER sensor(Yamaguchi et al., 1998) in the dry lake beds and salt lake every year since 1995 (Figure 2). Railroad valley playa is one of our main calibration sites, which is located at $38.505^{\circ} \mathrm{N}$, $115.690^{\circ} \mathrm{W}, 1436$ [m] altitude in east-central Nevada, US (Figure 1). The Radiometric Calibration Test Site (RadCaTS) at Railroad Valley, Nevada was developed by the University of Arizona, which is one of RadCalNet sites. RadCaTS is located at the adjacent area of our calibration site. Many calibration groups in various satellite mission have used Railroad valley playa as calibration site (MODIS, ASTER, GOSAT, MISR, OCO, Land- sat, Setinel, and so on)(Thome et al., 2003; Kuze et al., 2011; Bruegge et al., 2014; Czapla-Myers et al., 2017).

Calibration sites need to be homogeneous and flat, and it is preferable that the characteristic of surface reflectance from visible to short-wavelength infrared region is stable. In addition to the logistics and accessibility, the weather and atmospheric conditions of the sites are also important. The objective of this research is to understand the cloud cover trend over the calibration site, Railroad valley playa, by using MODIS cloud mask (MOD35_L2 and MYD35_L2) products.

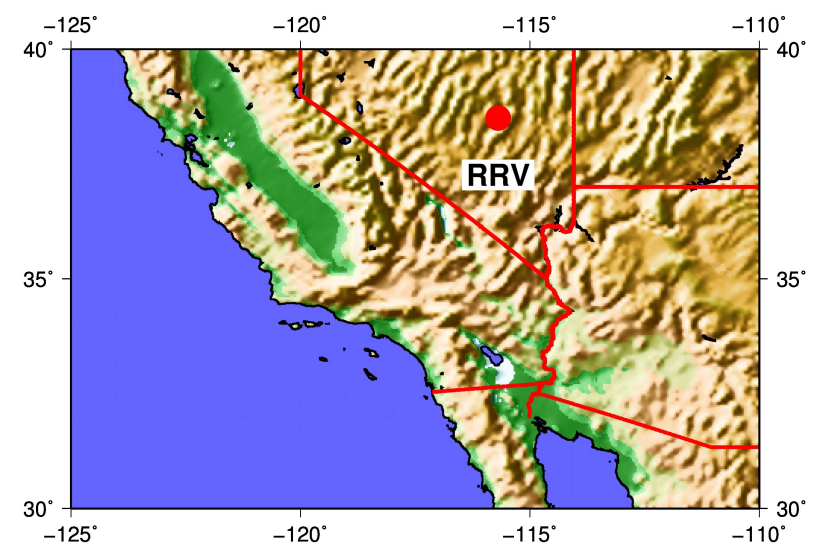

Figure 1. Location of Railroad Valley Playa

\section{METHODOLOGY}

We use the Terra MODIS Cloud Mask product (MOD35_L2) from 2000 to 2018, and the Aqua MODIS product (MYD35_L2) from 2002 to 2018 in this research. MOD35_L2 and MYD35_L2 


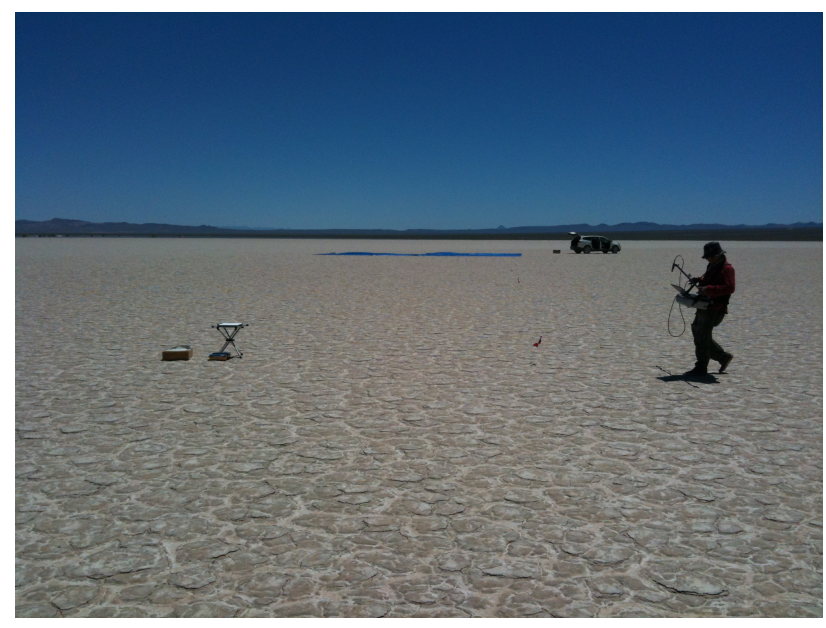

Figure 2. Vicarious calibration experiment in Railroad valley playa (Jun, 2012)

are daily global Level 2 products, and provide 48-bit ( 6 byte) field in each 1-km pixel(Strabala, 2005, Ackerman, 2010). The version of all products we used is collection 6.1 , which is the latest MODIS cloud mask product. There are four types in "Unobstructed FOV Confidence Flag" of these products, which are Cloudy, Uncertain, Probably Clear, and Confident Clear (Table 1). This research define "Confident Clear" and "Probably Clear" as clear-sky, and we simply calculatete the clear sky ratio $r(t)$ as below, We extracted the cloud flag values over our measurement sites in Railroad valley playa.

Table 1. Bit fields within first bite of the 48-bit MODIS cloud mask (MOD35_L2, MYD35_L2)

\begin{tabular}{c|c|c}
\hline Bit field & Description & Key \\
\hline \hline 0 & Cloud Mask Flag & $\begin{array}{c}0=\text { Not determined } \\
1=\text { Determined }\end{array}$ \\
\hline 2,1 & Unobstructed & $00=$ Cloudy \\
& FOV Quality Flag & $\begin{array}{c}01=\text { Uncertain } \\
10=\text { Probably Clear } \\
11=\text { Confident Clear }\end{array}$ \\
& & $0=$ Night \\
& & $1=$ Day \\
\hline 3 & Day or Night Path & $1=$ Yes \\
& & $0=$ Yes \\
& Sunglint Path & $1=$ No \\
\hline 5 & Snow/Ice & $00=$ Water \\
& Background Path & $01=$ Coastal \\
& Land or Water Path & $11=$ Desert \\
\hline 7,6 & &
\end{tabular}

$$
r(t)=\frac{N(t)}{5} .
$$

\footnotetext{
$t \quad: \quad$ Day Of Year (DOY, $\mathrm{t}=3 \sim 363$ or 364 )

$r(t)$ : Clear sky ratio at $t$

$N(t)$ : The number of clear sky days ("Probably Clear"
}

\author{
or "Confident Clear" in MOD35_L2 \\ or MYD35L2 flag) in five days $(t-2 \sim t+2)$
}

All products are downloaded from the Level-1 and Atmosphere Archive \& Distribution System (LAADS) Distributed Active Archive Center (DAAC), NASA, and 10,838 MOD35_L2 and 9,721 MYD35_L2 products were processed.

\section{RESULTS}

Figure 3 shows mean values of clear sky ratio $r(t)$ using MOD35_L2 in 2000-2018 and MYD35_L2 in 2002-2018 for each day. Figure 4 and Figure 5 depict every 5 years mean values of clear sky ratio $r(t)$ from 2004 to 2018 in the morning and afternoon, respectively. Table 2 shows the summary of clear sky ratio $r(t)$ statistics in four seasons.

Highest clear sky ratio, $r(t)(>0.900)$ in the morning is $t=$ $176 \sim 261$, which means that date on which we conduct the vicarious calibration experiment over Railroad valley playa should be set to arround Jun 25 Sep 18. On the other hand, there are no highest $r(t)$ in the afternoon, and higher $r(t)(>0.850)$ in the afternoon is $t=170$ (Jun 19) $\sim 268$ (Sep 25). $r(t)$ of MOD35_L2 is slightly higher than MYD35L2, that difference is approximately $6.5 \%$. Figure 4 and Figure 5 indicate that past trend of clear sky ratio is almost same as the current trend.

Table 2. Clear sky ratio derived from MOD35_L2 (2000-2018) and MYD35_L2(2002-2018) in four seasons

\begin{tabular}{c|c|c|c}
\hline Season & Product & Mean & $\begin{array}{c}\text { Standard } \\
\text { Deviation }\end{array}$ \\
\hline \hline \multirow{2}{*}{$\begin{array}{c}\text { Spring } \\
\text { (Mar,Apr,May) }\end{array}$} & MOD35_L2 & 0.641 & 0.106 \\
\cline { 2 - 4 } & MYD35_L2 & 0.584 & 0.090 \\
\hline $\begin{array}{c}\text { Summer } \\
\text { (Jun,Jul,Aug) }\end{array}$ & MOD35L2 & 0.866 & 0.045 \\
\cline { 2 - 4 } MYD35_L2 & 0.801 & 0.061 \\
\hline $\begin{array}{c}\text { Autumn } \\
\text { (Sep,Oct,Nov) }\end{array}$ & MOD35_L2 & 0.670 & 0.192 \\
\cline { 2 - 4 } MYD35_L2 & 0.669 & 0.153 \\
\hline $\begin{array}{c}\text { Spring } \\
\text { (Dec,Jan,Feb) }\end{array}$ & MOD35_L2 & 0.343 & 0.048 \\
\cline { 2 - 4 } & MYD35_L2 & 0.387 & 0.077 \\
\hline
\end{tabular}

\section{CONCLUSIONS}

We invedtigated the clear sky ratio over Railroad valley playa, which is the vicarious calibration site for various satelite missions.

The preferable date on which conduct the vicarious calibration experiments over Railroad valley playa is from late June to late September. Experiments in the morning could have slightly advantages to afternoon experiments.

Although vicarious calibration is very accurate calibration techniques for satellite optical sensors, this needs various resources (human, time, cost, and so on). The results in this research is very useful information for vicarious calibration plan. And, the methodology of clear sky ratio using MODIS cloud mask products in this study could be also applicable to assessnebt of validation sites. 


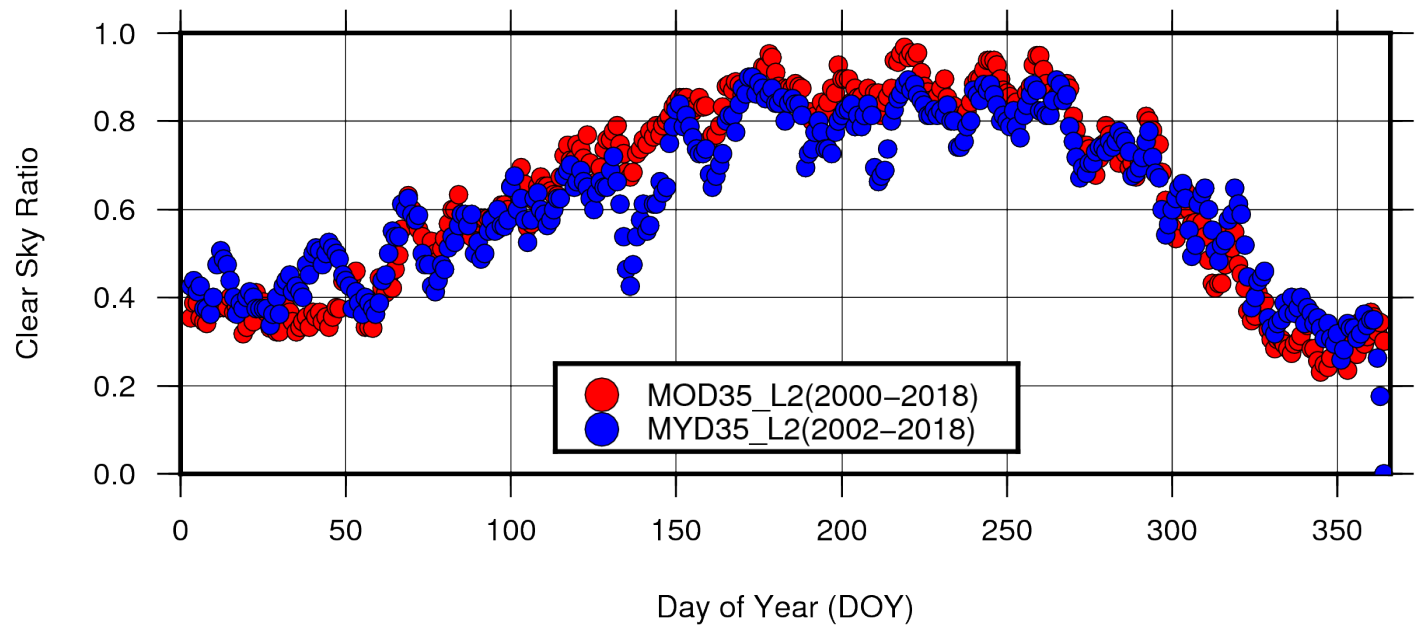

Figure 3. Mean value of clear sky ratio $r(t)$ over Railroad Valley

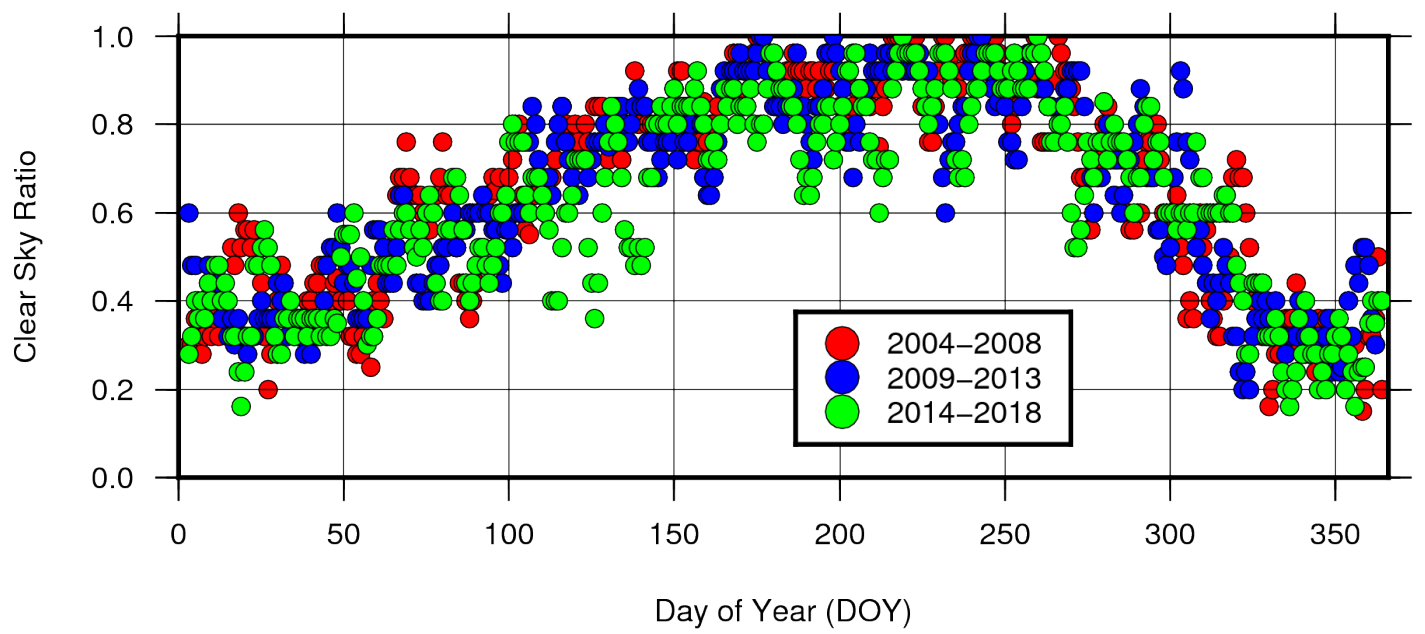

Figure 4. Mean value for a five year period of clear sky ratio $r(t)$ over Railroad Valley (MOD35_L2)

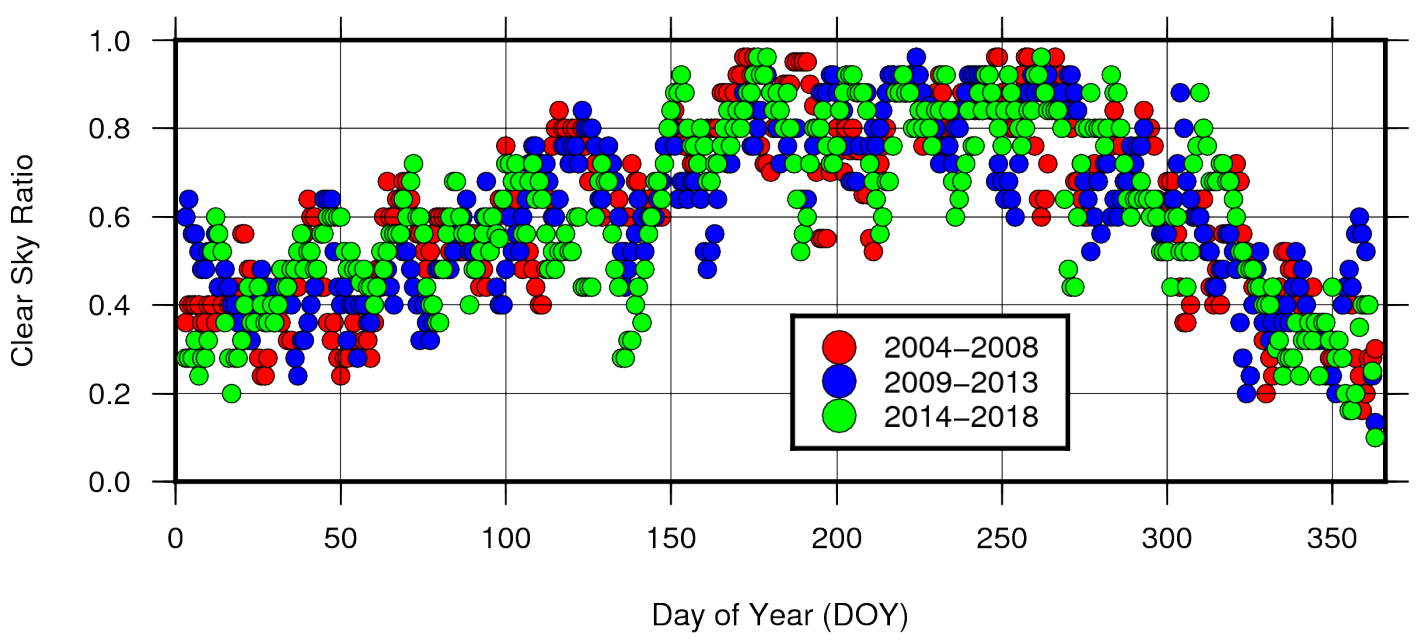

Figure 5. Mean value for a five year period of clear sky ratio $r(t)$ over Railroad Valley (MYD35_L2) 


\section{ACKNOWLEDGEMENTS}

The Terra and Aqua MODIS Atmosphere L2 Cloud Mask Products were acquired from the Level-1 and Atmosphere Archive \& Distribution System (LAADS) Distributed Active Archive Center (DAAC), located in the Goddard Space Flight Center in Greenbelt, Maryland (https://ladsweb.nascom.nasa.gov/).

\section{REFERENCES}

Ackerman, S., 2010. Discriminating clear-sky from cloud with modis. Algorithm Theoretical Basis Document MOD35 Version 6.1 .

Bruegge, C. J., Val, S., Diner, D. J., Jovanovic, V., Gray, E., Di Girolamo, L. and Zhao, G., 2014. Radiometric stability of the multi-angle imaging spectroradiometer (misr) following 15 years on-orbit. In: Earth Observing Systems XIX, Vol. 9218, International Society for Optics and Photonics, p. 92180N.

Czapla-Myers, J., Bouvet, M. and Wenny, B., 2016. The radiometric calibration network (radcalnet): a global calibration and validation test site network. In: AGU Fall Meeting Abstracts.

Czapla-Myers, J., McCorkel, J., Anderson, N. and Biggar, S., 2017. Earth-observing satellite intercomparison using the radiometric calibration test site at railroad valley. Journal of Applied Remote Sensing 12(1), pp. 012004.

Kuze, A., O’Brien, D. M., Taylor, T. E., Day, J. O., O’Dell, C. W., Kataoka, F., Yoshida, M., Mitomi, Y., Bruegge, C. J., Pollock, H. et al., 2011. Vicarious calibration of the gosat sensors using the railroad valley desert playa. IEEE Transactions on Geoscience and Remote Sensing 49(5), pp. 1781-1795.

Slater, P. N., Biggar, S. F., Thome, K. J., Gellman, D. I. and Spyak, P. R., 1996. Vicarious radiometric calibrations of eos sensors. Journal of Atmospheric and Oceanic Technology 13(2), pp. 349-359.

Strabala, K. I., 2005. MODIS cloud mask user's guide. University of Wisconsin-Madison.

Thome, K. J., Czapla-Myers, J. S. and Biggar, S. F., 2003. Vicarious calibration of aqua and terra modis. In: Earth Observing Systems VIII, Vol. 5151, International Society for Optics and Photonics, pp. 395-406.

Yamaguchi, Y., Kahle, A., Tsu, H., Kawakami, T. and Pniel, M., 1998. Overview of Advanced Spaceborne Thermal Emission and ReflectionRadiometer (ASTER). IEEE Transactions on Geoscience and Remote Sensing 36(4), pp. 1062-1071.

Revised Jan 2019 